\title{
Secretion of small/microRNAs including miR-638 into extracellular spaces by sphingomyelin phosphodiesterase 3
}

\author{
SHIORI KUBOTA $^{1 *}$, MITSURU CHIBA $^{2,3^{*}}$, MIKI WATANABE $^{1}$, MAKI SAKAMOTO $^{1}$ and NARUMI WATANABE ${ }^{1}$ \\ ${ }^{1}$ Department of Medical Technology, Hirosaki University School of Health Sciences; ${ }^{2}$ Department of Biomedical Sciences, \\ Division of Medical Life Sciences, ${ }^{3}$ Research Center or Biomedical Sciences, Hirosaki University Graduate \\ School of Health Sciences, Hirosaki, Aomori 036-8564, Japan
}

Received August 28, 2014; Accepted October 24, 2014

DOI: $10.3892 /$ or.2014.3605

\begin{abstract}
A recent study demonstrated that intracellular small/microRNAs are released from cells, and some of these extracellular RNAs are embedded in vesicles, such as ceramide-rich exosomes, on lipid-bilayer membranes. In the present study, we examined the effects of sphingomyelin phosphodiesterase 3 (SMPD3), which generates ceramide from sphingomyelin, on the release of small/microRNAs from intracellular to extracellular spaces. In these experiments, SW480 human colorectal and HuH-7 human hepatocellular cancer cells were cultured for $48 \mathrm{~h}$ in serum-free media. Culture supernatants were then collected, and floating cells and debris were removed by centrifugation and filtration through a $0.22-\mu \mathrm{m}$ filter. Extracellular small RNAs in purified culture supernatants were stable for 4 weeks at room tempera-

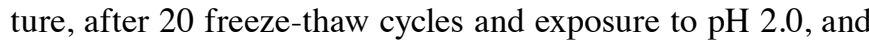
were resistant to ribonuclease A degradation. Amino acid sequence analyses of SMPD3 showed high homology between mammals, indicating evolutionary conservation. Therefore, to investigate the mechanisms of cellular small/microRNA export, SW480 and HuH-7 cells were treated with the SMPD3 inhibitor GW4869 in serum-free media. Culture supernatants were collected for microarray and/or reverse transcription quantitative polymerase chain reaction (RT-qPCR) experiments. The number of microRNAs in culture supernatants was decreased following treatment with GW4869. Among these, extracellular and intracellular miR-638 were dose-dependently
\end{abstract}

Correspondence to: Dr Mitsuru Chiba, Department of Biomedical Sciences, Division of Medical Life Sciences, Hirosaki University Graduate School of Health Sciences, 66-1 Hon-cho, Hirosaki, Aomori 036-8564, Japan

E-mail: mchiba32@cc.hirosaki-u.ac.jp

${ }^{*}$ Contributed equally

Key words: microRNA, miR-638, extracellular RNA, sphingomyelin phosphodiesterase 3, neutral sphingomyelinase 2, GW4869, exosome, extracellular vesicle decreased and increased, respectively. These data suggest that SMPD3 plays an important role in the release of microRNAs into extracellular spaces.

\section{Introduction}

MicroRNAs of 20-25 nucleotides act as post-transcriptional regulators of gene expression, and their localization suggests that they primarily function in the cytoplasm. Recently, a number of microRNAs were found in extracellular spaces (1), and some of these were embedded in extracellular vesicles such as exosomes (2). However, it has been suggested that some extracelluar microRNAs form complexes with Argonaute 2 (Ago2), high-density lipoprotein (HDL) and other RNA-binding proteins (3-6). Therefore, microRNAs may be present in various bound forms in extracellular spaces. Diagnostic biomarkers were recently identified in body fluids such as serum, plasma, urine, milk and saliva (7-11). Among these biomarkers, some extracellular RNAs were shown to be uniquely stable in the presence of ribonuclease (12-14). However, these data require further validation in focused studies of extracellular microRNA stability.

Exosomes are extracellular vesicles, $\sim 40-200 \mathrm{~nm}$ in diameter, which are secreted from epithelial (15), endothelial (16), cancer (17), dendritic (18), and mesenchymal stem cells (19), as well as B lymphocytes (20). Exosome secretion has been identified in human and mouse cells in vitro (1). However, few studies have demonstrated RNA secretion in other organisms.

Although the mechanisms of exosome biogenesis remain to be adequately defined, current models suggest that exosomes are formed within multivesicular bodies (MVBs) (21), which are formed during maturation of early into late endosomes, with concomitant and corresponding accumulation of intraluminal vesicles (ILVs) (22). Endosomal sorting complexes required for transport (ESCRT) machinery are also responsible for generating vesicles in MVBs through a process known as endosome budding (23). In addition, ceramide is reportedly involved in an ESCRT-independent process of exosome generation (24). Ceramide, which is generated from sphingomyelin by neutral sphingomyelinase 2 (nSMase2), is found in lipid components of exosome membranes (25), and is encoded by the sphingomyelin phosphodiesterase 3 (SMPD3) 
Table I. Primer sequences for RT-qPCR.

\begin{tabular}{llcc}
\hline Gene name & \multicolumn{1}{c}{ Primer sequence } & Size (nt) & Amplicon size (bp) \\
\hline SMPD3 & F: 5'-CGTCGTCTGTGGAGATTTCA-3' & 20 & 76 \\
SMPD3 & R: 5'-GGTGAACAGGGAGTGTTGCT-3' & 20 & 66 \\
GAPDH & F: 5'-AGCCACATCGCTCAGACAC-3' & 19 & \\
GAPDH & R: 5'-GCCCAATACGACCAAATCC-3' & 19 & \\
\hline
\end{tabular}

gene. Although this enzyme has been shown to be involved in the secretion of small RNAs such as microRNAs (26), which small/microRNAs are released following the actions of nSMase 2 remains to be determined.

In the present study, we investigated the stability of extracellular small RNAs against external factors including ribonuclease A (RNase A), long-term incubation, freeze-thaw, and $\mathrm{pH}$ change using $\mathrm{HuH}-7$ human hepatocellular cancer cells. In addition, we examined the evolutionary conservation of SMPD3 in mammals and determined the effects of an SMPD3 inhibitor on the release of small/microRNAs from HuH-7 and SW480 human colorectal cancer cells.

\section{Materials and methods}

Cell lines and culture. HuH-7 human hepatocellular cancer cells (JCRB0403) were purchased from the Health Science Research Resources Bank (Osaka, Japan). The human colorectal cancer cell line SW480 (CCL-228) was purchased from the American Type Culture Collection (ATCC, Manassas, VA, USA). HuH-7 cells were cultured in Dulbecco's minimal essential medium (D-MEM; Wako, Tokyo, Japan) supplemented with $10 \%$ fetal bovine serum (FBS; Life Technologies, Carlsbad, CA, USA), $100 \mathrm{U} / \mathrm{ml}$ penicillin, and $100 \mu \mathrm{g} / \mathrm{ml}$ streptomycin. SW480 cells were cultured in RPMI-1640 medium (Wako) supplemented with $10 \%$ FBS, $100 \mathrm{U} / \mathrm{ml}$ penicillin, and $100 \mu \mathrm{g} / \mathrm{ml}$ streptomycin. The cells were cultured at $37^{\circ} \mathrm{C}$ in a $5 \% \mathrm{CO}_{2}$ atmosphere.

Purification of culture supernatants. SW480 and HuH-7 cells were plated on collagen-coated $10-\mathrm{cm}$ dishes at $1 \times 10^{6}$ cells/dish in culture media. After $72 \mathrm{~h}$, the culture media were discarded and the cells were washed three times in serum-free culture media. Serum-free culture media supplemented with the SMPD3 inhibitor GW4869 (Sigma-Aldrich, St. Louis, MO, USA) at final concentrations of $0,1.0,3.3$, and $10.0 \mu \mathrm{M}$ were then added at $10 \mathrm{ml}$ per dish, and the cells were cultured for $48 \mathrm{~h}$. Cell culture media were then collected and centrifuged at $300 \mathrm{x} \mathrm{g}$ at $4^{\circ} \mathrm{C}$ for 3 min to remove floating cells. Supernatants were centrifuged at $2,000 \mathrm{x}$ g at $4^{\circ} \mathrm{C}$ for $15 \mathrm{~min}$ and were collected in new tubes. Culture supernatants were also centrifuged at $12,000 \mathrm{x} \mathrm{g}$ at $4^{\circ} \mathrm{C}$ for $35 \mathrm{~min}$ to remove cell debris, and the supernatants were collected in new tubes and filtered using $0.22-\mu \mathrm{m}$ filters. Extracellular RNAs in the supernatants were then isolated using Isogen II (NipponGene, Tokyo, Japan).
RNA extraction. Extracellular and intracellular RNAs from SW480 or HuH-7 cells were isolated using Isogen II (NipponGene) according to the manufacturer's instructions. The sizes of extracted RNAs were determined using an Agilent 2100 Bioanalyzer and Agilent RNA 6000 Pico kits (both from Agilent Technologies, Foster City, CA, USA) according to the manufacturer's instructions.

Microarray analysis. Species of extracellular microRNAs were distinguished by labeling with Hy5 fluorescent dye using a miRCury LNA ${ }^{\mathrm{TM}}$ microRNA Hy5 Power labeling kit (Exiqon, Copenhagen, Denmark). Microarray analyses were then conducted using a Toray microRNA microarray system. Toray 3D-Gene human miRNA oligo chips (Toray, Tokyo, Japan) were hybridized with Hy5-labeled microRNAs in hybridization solution at $32^{\circ} \mathrm{C}$ for $16 \mathrm{~h}$ using a hybridization oven. Hybridized microarray chips were then washed in a wash buffer according to the manufacturer's instructions, and images of fluorescent signals were captured using a Toray 3D-gene scanner 3000 (Toray).

Reverse transcription polymerase chain reaction (RT-PCR) and $R T$ quantitative PCR (RT-qPCR). To investigate SMPD3 mRNA expression in SW480 and HuH-7 cells, cDNAs were synthesized from isolated RNAs using High Capacity cDNA reverse transcriptase kits according to the manufacturer's instructions. Subsequently, qPCR for mRNAs was performed using $2 \mathrm{X}$ Power SYBR-Green master mix, $10.0 \mu \mathrm{M}$ forward and reverse primers (Table I), and a StepOne Plus real-time PCR system (all from Life Technologies), under the following conditions: $10 \mathrm{~min}$ at $95^{\circ} \mathrm{C}$, followed by 40 cycles at $95^{\circ} \mathrm{C}$ for $15 \mathrm{sec}$ and $60^{\circ} \mathrm{C}$ for $60 \mathrm{sec}$. GAPDH was used as an internal control. Expression levels were determined using the comparative $\mathrm{Ct}$ method and were normalized to those from SW480 cells. Amplified fragments were then detected on 4\% agarose gel electrophoresis containing ethidium bromide using a ChemiDoc XRS system and Quantity One software (both from Bio-Rad, Hercules, CA, USA).

Expression levels of extracellular and intracellular microRNAs from SW480 and HuH-7 cells were analyzed using cDNAs that were synthesized from microRNAs using TaqMan microRNA RT kits and the prescribed 5X RT primer (both from Life Technologies) according to the manufacturer's instructions. Subsequently, qPCR for microRNAs was performed using FastStart TaqMan probe master (Roche Diagnostics, Basel, Switzerland), a 20X probe, and a StepOne Plus real-time PCR 

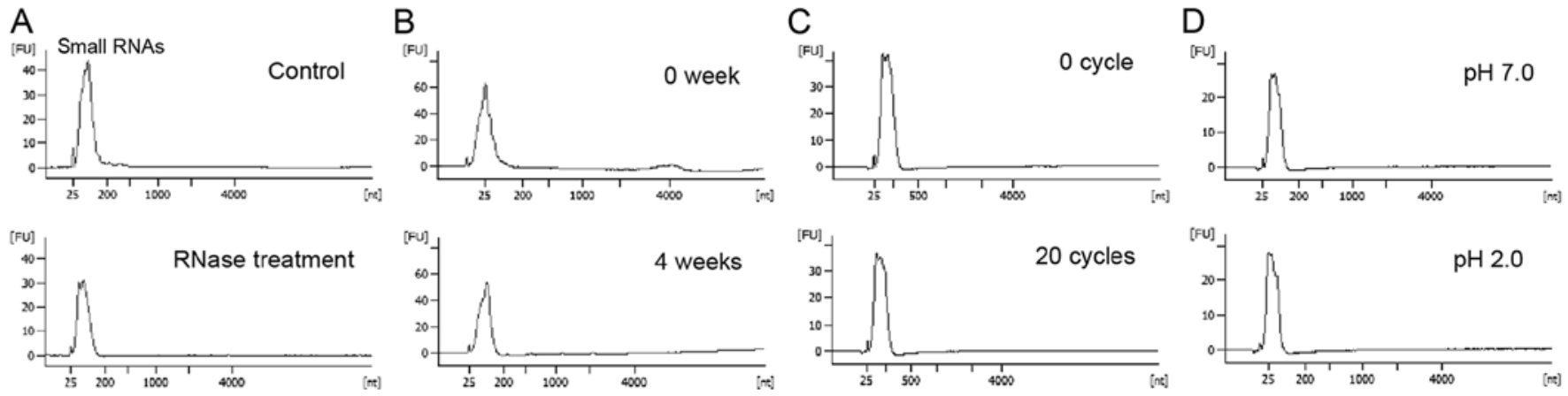

Figure 1. Extracellular small RNAs in cell culture media are stable against several external conditions. (A-D) Stability of extracellular small RNAs from HuH-7 cells, which were seeded at $1 \times 10^{5}$ cells/well in 12 -well plates. After $24 \mathrm{~h}$, cells were washed three times in serum-free media. Serum-free (1 ml) media were then added, and the cells were incubated at $37^{\circ} \mathrm{C}$ for $48 \mathrm{~h}$. Culture supernatants were then collected and purified by centrifugation and filtration. Culture supernatants of $\mathrm{HuH}-7$ cells were (A) treated with a final concentration of $4 \mu \mathrm{g} / \mathrm{ml}$ of ribonuclease A (RNase A) at $37^{\circ} \mathrm{C}$ for 30 min, (B) incubated for 4 weeks at room temperature, (C) subjected to 20 freeze-thaw cycles, and (D) were subjected to a pH decrease to 2.0 . Small RNAs were extracted from $200 \mu 1$ aliquots and were detected using an Agilent bioanalyzer.

system (Life Technologies) under the following conditions: $10 \mathrm{~min}$ at $95^{\circ} \mathrm{C}$, followed by 40 cycles at $95^{\circ} \mathrm{C}$ for $15 \mathrm{sec}$ and $60^{\circ} \mathrm{C}$ for $60 \mathrm{sec}$. RNAs were isolated from $200-\mu 1$ aliquots of culture supernatants following the addition of $1 \mu \mathrm{l}$ of $5 \mathrm{nM}$ cel-miR-39. Cel-miR-39 was used as an external control and U6 small nuclear RNA (snRNA) was used as an internal control. Expression levels were determined using the comparative $\mathrm{Ct}$ method.

Multiple alignments of SMPD3 amino acid sequences. Amino acid sequences for Homo sapiens SMPD3, NP_061137.1; Pan troglodytes SMPD3, XP_001167790.1; Mus musculus SMPD3, NP_067466.1; and Bos taurus SMPD3, NP_001179292.1, were obtained from the NCBI database (http://www.ncbi.nlm.nih. gov), and were subjected to multiple alignment analysis using Genetyx 10 software (Genetyx, Tokyo, Japan).

Statistical analysis. Data are presented as the mean \pm standard error of the mean (SEM). Multiple group comparisons were performed using one-way analysis of variance (ANOVA), followed by post hoc pair-wise comparisons of significant differences using Dunnett's test. Differences were considered significant when $\mathrm{P}<0.01$.

\section{Results and Discussion}

Extracellular small RNAs are stable against changes in various conditions. Encapsulation of released cellular small RNAs in exosomes likely allows high stability against changes in several conditions (12-14). Accordingly, small RNAs in purified supernatants from $\mathrm{HuH}-7$ cells were stable through RNase A treatment, long-term incubation, cycles of freezing and thawing and $\mathrm{pH}$ changes.

In experiments conducted in this study, serum-free culture supernatants from $\mathrm{HuH}-7$ cells were purified by centrifugation and filtration and were incubated with RNase A at a final concentration of $0.4 \mu \mathrm{g} / \mathrm{ml}$ for $10 \mathrm{~min}$ at $37^{\circ} \mathrm{C}$. After extraction of total RNAs from culture supernatants, a peak for small RNAs of 25-200 nt was detected using an Agilent bioanalyzer (Fig. 1A). However, in culture supernatants, small RNAs were stable after incubation at room temperature for 4 weeks, 20 cycles of freezing and thawing (room temperature to $-80^{\circ} \mathrm{C}$ ), and reduction of $\mathrm{pH}$ to 2.0 (Fig. 1B-D). These data indicate high stability of small RNAs in culture supernatants.

Evolutionary conservation of SMPD3 in mammals. SMPD3 is reportedly involved in the secretion of microRNAs (26). The present analyses of various mammalian SMPD3 sequences (Homo sapiens, Pan troglodytes, Mus musculus and Bos taurus) indicated high sequence homology (Fig. 2), with an amino acid sequence identity of 99.69, 91.02 and $89.50 \%$ between Homo sapiens and Pan troglodytes, Mus musculus, Bos Taurus, respectively. Moreover, two hydrophobic segments, two palmitoylation sites and the catalytic domain were highly conserved between examined mammals (Fig. 2). These analyses suggest that SMPD3 may have similar functions across these species.

Small/microRNAs, such as miR-638, are secreted into extracellular spaces via a ceramide-dependent mechanism. Although nSMase 2 produces ceramide from sphingomyelin (25), it is reportedly involved in the secretion of small RNAs such as microRNAs (26). Thus, we investigated the relationship between small RNA secretion and SMPD3 mRNA expression in SW480 and HuH-7 cells. In the RT-qPCR experiments, SMPD3 mRNA expression in HuH-7 cells was 28.62-fold higher than that in SW480 cells (Fig. 3A). Moreover, peak RNA release from $\mathrm{HuH}-7$ cells was higher than that of SW480 cells (Fig. 3B), and corresponded with high SMPD3 mRNA expression.

In the present study, concentrations of small RNAs in culture supernatants were determined following treatment of HuH-7 or SW480 cells with non-competitive SMPD3 inhibitor GW4869 at a final concentration of $10.0 \mu \mathrm{M}$. In these experiments, small RNA contents were markedly decreased after $48 \mathrm{~h}$ (Fig. 3B), suggesting that SMPD3 is important in small RNA secretion.

In subsequent experiments, the amounts and species of microRNAs in culture supernatants from GW4869-treated HuH-7 cells were analyzed using a Toray microRNA micro- 


\begin{abstract}
Hydrophobic segment Palmitoylation site Hydrophobic segment
Homo sapiens 1:MVLYTTPFPNSCLSALHCVSWALIFPCYWLVDRLAASFIPTTYEKRQRADDPCCLQLLCTALFTPIYLALLVASLPFAFLGFLFWPPLSARRPYIYSRLEDKGLAGGAALLSEWKGTGP 120 Pan troglodytes 1:MVLYTTPFPNSCLSALHCVSWALIFPCYWLVDRLAASFIPTTYEKRQRADDṔPCCLQLLCTALFTPIYLALLVASLPFAFLGFLFWSPLQSARRPYIYSRLEDKGLAGGAALLSEWKGTGP 120 Mus musculus 1:MVLYTTPFPNSCLSALHAVSWALIFPCYWLVDRLLASFIPTTYEKRQRADD'PCCLQLFCT'VLFTPVYLALLVAALPFAFLGFIFUSPLQSARRPYSYSRLEDKNPAGGAALLSEWKGTGA 120 Bos taurus 1:MVLYTTPFPSCLSALHAVSWALIFPCYWLADRLLASFIPTTYEKRQRADDPPCYLQLLCI'VLFTPVYLALLVASLPFAFLGFLLWSPLQSARRPYVYSRLEDKGPTGGAALLSEWKGTGP 120

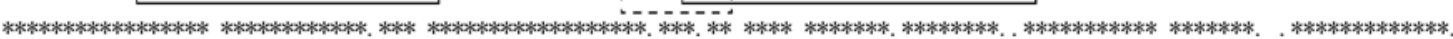

Homo sapiens 121 :GKSFCFATANVCLLPDSLARVNNLFNTQARAKEIGQRIRNGAARPQIKIYIDSPTNTSISAASFSSLVSPQGGDGVARAVPGSIKRTASVEYKGDGGRHPGDEAANGPASGDPVDSSSPE 240 Pan troglodytes 121:GKSFCFATANVCLLPDSLARVNNLFNTQARAKEIGQRIRNGAARPQIKIYIDSPTNTSISAASFSSLVSPQGGDGVARAVPGSIKRTASVEYKGDGGRHPGDEAANGPASGDPVDSSSPE 240 Mus musculus 121:GKSFCFATANVCLLPDSLARLNNVFNTQARAKEIGQRIRNGAARPQIKIYIDSPTNTSISAASFSSLVSPQGGDG-SRAVPGSIKRTASVEYKGDGGRHPSDEAANGPASGEQAD-GSLE 238 Bos taurus 121: GKSFCFATANLCLLPDSLARLNNVFNTQARAKEIGQRIRNGASRPQIKIYIDSPTNTSISAASFSSLVSPQGSDGVPRAVPGSIKRTASVEYKGDGGRHPSDEAANGLASGDPADGGNLE 240

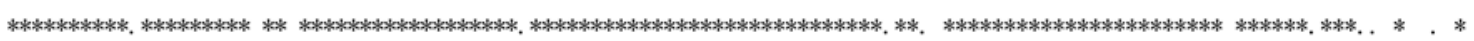

Homo sapiens 241:DACIVRIGGEEGGRPPEADDPVPGGQARNGAGGGPRGQTPNHNQQDGDSGSLGSPSASRESLVKGRAGPDTSASGEPGANSKLLYKASVVKKAAARRRF Pan troglodytes 241:DACIVRISGEEGGRPPEADDPAPGGQARNGAGGGPRGQTPNHNQQDGDSGSLGSPSASRESLVKGRAGPDTSASGEPGANSKLLYKASVVKKAAARRRRHPDEAFDHEVSAFFPANLDFL 360 Mus musculus 239:DSCIVRIGGEEGGRPQEADDPAAGSQARNGAGGTPKGQTPNHNQRDGDSGSLGSPSASRESLVKARAGQDSGGSGEPGANSKLLYKTSVVKKAAARRRRHPDEAFDHEVSAFFPANLDFL 358 Bos taurus 241:DACIVRISGDEGGRPPEAGDPANGGQARNGAGGGPRGQTPNHSQQDGDSGSLGSPSASRESLVKGRSGAD-GGSGEPGANSKLPYKASVVKKAAMRRRRHPDEAFDHEVSAFFPANLDFL 359

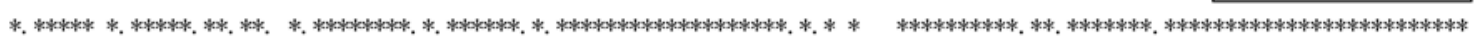

Palmitoylation site

Catalytic domain

Homo sapiens 361 : CLQEVFDKRAATKLKEQLHGYFEYILYDVGVYGCQGCCSFKCLNSGLLFASRYPIMDVAYHCYPNKCNDDALASKGALFLKVQVGSTPQDQRIVGYIACTHLHAPQEDSAIRCGQLDLLQ 480 Pan troglodytes 361: CLQEVFDKRAATKLKEQLHGYFEYILYDVGVY'GCQGCCSFKCLN'SGLLFASRYPIMDVAYHCYPNKCNDDALASKGALFLKVQVGSTPQDQRIVGYIACTHLHAPQEDSAIRCGQLDLLQ 480 Mus musculus 359:CLQEVFDKRAAAKLKEQLHGYFEYILYDVGVYGCHGCCNFKCLNSSGLFASRYPVMDVAYHCYPNGCSFDALASKGALFLKVQVGSTPQDQRIVGYIACTHLHAPPEDSAVRCEQLDLLQ 478 Bos taurus 360:CLQEVFDKRAAAKLKDQLHSYFEYILYDVGVYGGCHGCCSFKCLNSGLFFASRYPIMDVAYHCYPNGRFSDSLASKGALYLKVQVGSTPQDQRIVGYISCTHLHALSEDSDIRCEQLNMLQ 479

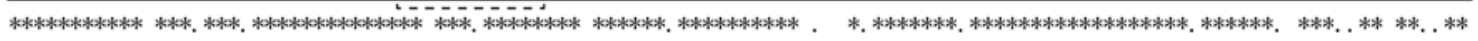

Homo sapiens 481 :DWLADFRKSTSSSSAANPEELVAFDVVCGDFNFDNCSSDDKLEQQHSLFTHYRDPCRLGPGEEKPWAIGTLLDTNGLYDEDVCTPDNLQKVLESEEGRREYLAFPTSKS--SGQKGRKEL 598 Pan troglodytes 481 :DWLADFRKSTSSSSAANPEELVAFDVVCGDFNFDNCSSDDKLEQQHSLFTHYRDPCRLGPGEEKPWAIGTLLDTNGLYDEDVCTPDNLQKVLESEEGRREYLAFPTSKS--SGQKGRKEL 598 Mus musculus 479:DWLADFRKSTSSTSTANPEELVVFDVICGDLNFDNCSSDDKLEQQHSLFTRYKDPCRLGPGEEKPWAIGTLLDTNGLYDEDVCTPDNLQKVLESEEGRREYLAFPTSKSPGAGQKGRKDL 598 Bos taurus 480 :DWLADFRKSTSSSSAANPEELVAFDIICGDFNFDNCSSDDKLEQQHSLFTRYKDPCRLGPGEEKPWAIGTLLDQDGLYDEEVCTPDNLQKVLESEEGRREYLAFPTSKSPGGGQKGRKEL 599

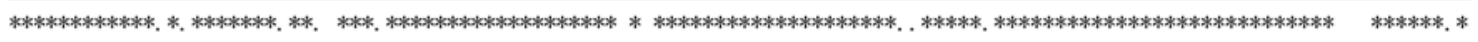

Homo sapiens 599: LKGNGRIDYMLHAEEGLCPDWKAEVEEFSFITQLSGLTDHLPVAMRIMVSSGEEEA 655

Pan troglodytes 599:LKGNGRIDYMLHAEEGLCPDWKAEVEEFSFITQLSGLTDHLPVAMRLMVSSGEEEA 655

Mus musculus 599:LLKGNGRIDYMLHAEEGLCPDWKAEVEEFSFITQLSGLTDHLPVAMRLMVSAGEEEA 655

Bos taurus 600:LKGNGRIDYMLHGEEGLYPDWKAEVEEFSFITQLSGLTDHLPVAMRLMVSAGDDEA 656

Figure 2. Evolutionary conservation of sphingomyelin phosphodiesterase 3 (SMPD3) in mammals. Amino acid sequence alignment analyses of SMPD3; two hydrophobic segments, two palmitoylation sites, and a catalytic domain were highly conserved in Homo sapiens, Pan troglodytes, Mus musculus, and Bos taurus. Asterisks indicate matched amino acids in all 4 sequences, while dots indicate matched amino acids in 3 of 4 mammals.

array system. MicroRNA expression profiles following treatment with 0 and $10.0 \mu \mathrm{M} \mathrm{GW} 4869$ for $48 \mathrm{~h}$ are shown in a scatter plot (Fig. 3C). Various microRNAs, including miR-638, were decreased in culture supernatants from GW4869-treated cells (Table II).

Subsequent RT-qPCR experiments showed a significant decrease in miR-638 expression in the SW480 and HuH-7 cells and supernatants following treatment with GW4869 $(\mathrm{P}<0.01)$. Specifically, extracellular miR-638 expression in HuH-7 cells was decreased 3.92- and 16.67-fold in the presence of 3.3 and $10.0 \mu \mathrm{M}$ GW4869, respectively. In SW480 cells it was decreased 2.29-, 11.36- and 113.14-fold in the presence of $1.0,3.3$ and $10.0 \mu \mathrm{M}$ GW4869, respectively (Fig. 3D-E). By contrast, intracellular miR-638 expression was significantly increased 2.43-, 5.41- and 15.81-fold in the presence of 1.0,3.3, and 10.0 $\mu \mathrm{M}$ GW4869 in HuH-7 cells, and
5.01-, 7.00-, and 9.57-fold, respectively, in SW480 cells when compared with expression in the presence of $0 \mu \mathrm{M}$ GW4869 $(\mathrm{P}<0.01$; Fig. 3D-E). These data suggest that SMPD3 plays an important role in the release of a number of microRNAs, including miR-638, and that microRNAs accumulated in cells following the inhibition of exosome membrane formation by GW4869.

Small RNAs secretions are involved in the formation of exosomes, the regulation of vesicle trafficking, and the plasma membrane fusion of MVBs $(28,29)$. Exosome transport is considered a highly controlled process that involves a number of Rab GTPases. Accordingly, Rab11 overexpression has been shown to stimulate exocytosis (30), and Rab27a and Rab27b have been shown to control exosome secretion by regulating vesicle transport of MVBs to plasma membranes (31). In addition, secretion of exosomes containing small RNAs requires 
A
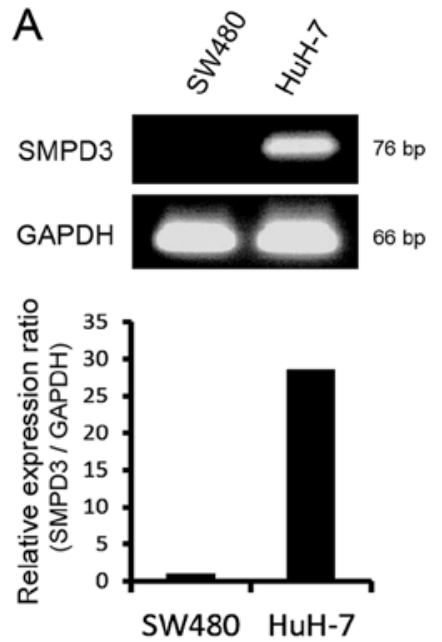

B
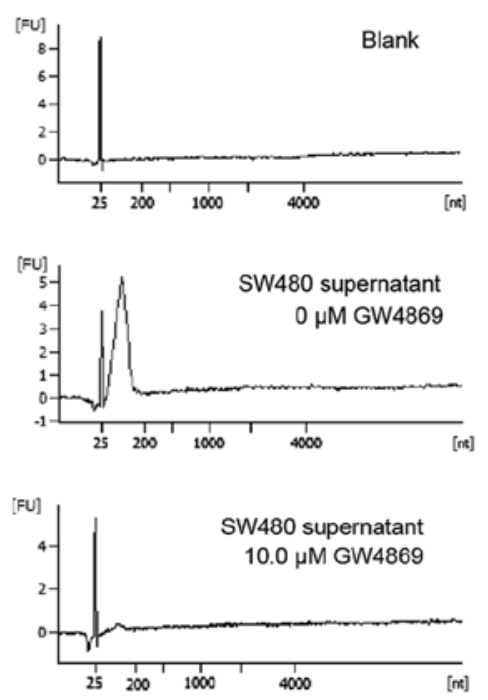
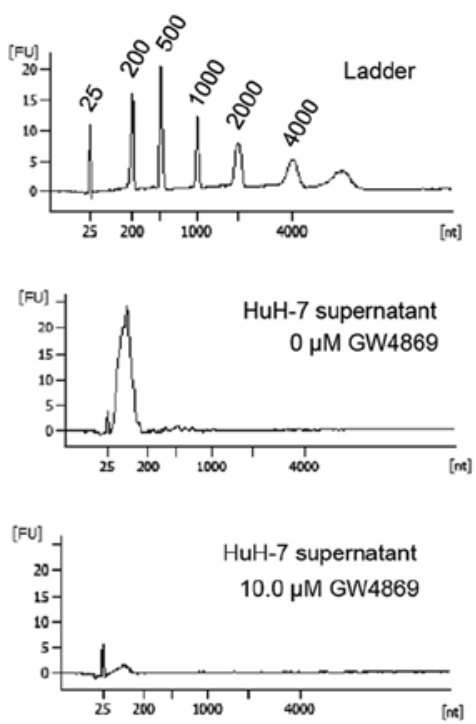

C

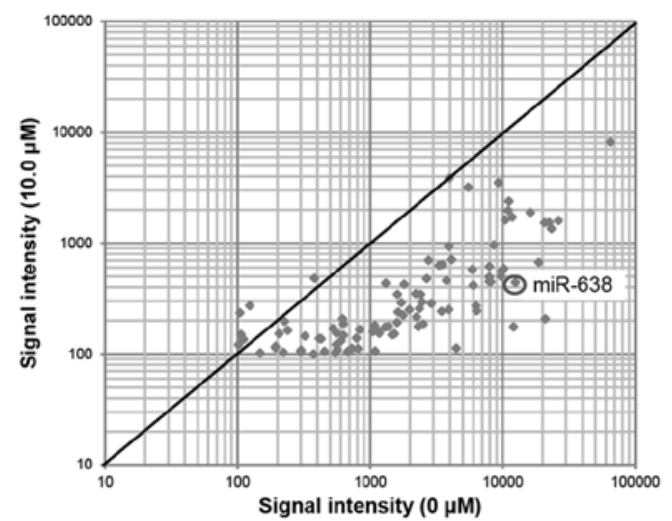

$\mathrm{D}$

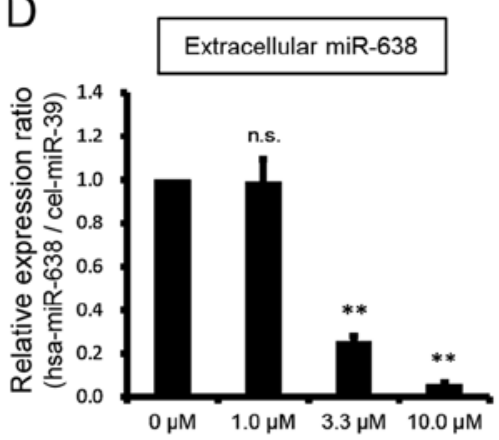

$\mathrm{E}$
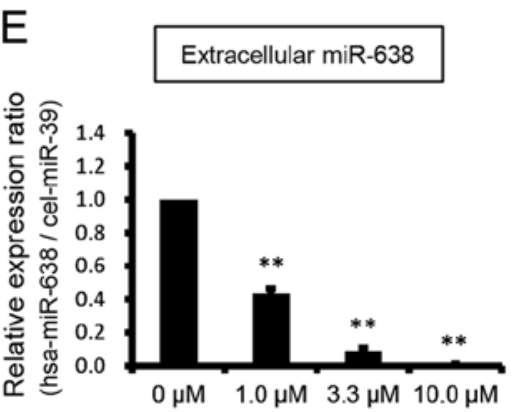

Figure 3. SMPD3 is involved in the secretion of small/microRNAs from cells. (A) Comparison of SMPD3 mRNA expression in SW480 and HuH-7 cells by electrophoresis of reverse transcription polymerase chain reaction (RT-PCR) products and RT quantitative PCR (RT-qPCR) using the primer pairs described in Table I. GAPDH was used as an internal control. Expression levels were determined using the comparative Ct method and were normalized to those of SW480 cells. (B) Effects on the quantities of small RNAs released from SW480 or HuH-7 cells after treatment with the SMPD3 inhibitor GW4869. SW480 and HuH-7 cells were seeded at $1 \times 10^{5}$ cells/well in 12 -well plates. After $24 \mathrm{~h}$, the cells were washed three times in serum-free media and were incubated in $1 \mathrm{ml}$ of serum-free media at $37^{\circ} \mathrm{C}$ for $48 \mathrm{~h}$. Culture supernatants were collected and purified by centrifugation and filtration and extracellular RNAs were isolated from 400- $\mu 1$ aliquots. Quantitative analysis of small RNAs in culture supernatants of SW480 or HuH-7 cells treated with GW4869 using an Agilent bioanalyzer. The quantities of small RNAs in culture supernatants decreased following treatment with $10.0 \mu \mathrm{M} \mathrm{GW} 4869$. (C) Scatter plot of microRNA expression in culture supernatants from HuH-7 cells after treatment with 0 and $10.0 \mu \mathrm{M}$ GW4869. Analyses were performed using a Toray microRNA microarray system. (D and E) Expression levels of extracellular and intracellular miR-638 in SW480 and HuH-7 cells treated with GW4869. Samples of cell pellets and supernatants from (D) HuH-7 cultures (each n=8) and (E) SW480 (each n=6) were prepared, RNA was extracted, and RT-qPCR analyses were performed. Cel-miR-39 and U6 small nuclear RNA (snRNA) were used as internal controls. Bars indicate the mean \pm standard error of the mean (SEM) values. Multiple comparisons were made using one-way ANOVA followed by Dunnett's multiple comparisons post hoc test. Double asterisks indicate significant differences ( $\mathrm{P}<0.01$ vs. $0 \mu \mathrm{M}$ ); n.s., not significant.

fusion of MVBs to plasma membranes, potentially involving soluble $\mathrm{N}$-ethylmaleimide-sensitive factor attachment protein receptor (SNARE) protein complexes (32). Future studies are required to clarify the mechanisms of RNA and exosome release into extracellular spaces.
In conclusion, extracellular small RNAs are comparatively stable due to their presence in exosomes. Moreover, the high evolutionary conservation of SMPD3 indicates an important role in the release of miR-638 and other microRNAs into extracellular spaces. 
Table II. The microRNA expression in culture supernatants of HuH-7 cells treated with 0 or $10.0 \mu \mathrm{M}$ GW4869 using a Toray microRNA microarray system.

\begin{tabular}{|c|c|c|c|c|c|}
\hline \multirow[b]{2}{*}{ microRNAs } & \multicolumn{2}{|c|}{ Raw signal intensity } & \multirow[b]{2}{*}{ microRNAs } & \multicolumn{2}{|c|}{ Raw signal intensity } \\
\hline & $0 \mu \mathrm{M}$ GW4869 & $10.0 \mu \mathrm{M} \mathrm{GW} 4869$ & & $0 \mu \mathrm{M}$ GW4869 & $10.0 \mu \mathrm{M}$ GW4869 \\
\hline hsa-miR-3960 & $65,098.0$ & $8,112.9$ & hsa-miR-4763-3p & $1,774.2$ & 223.5 \\
\hline hsa-miR-4787-5p & $26,349.0$ & $1,593.3$ & hsa-miR-4651 & $1,719.9$ & 290.3 \\
\hline hsa-miR-4508 & $23,348.0$ & $1,349.6$ & hsa-miR-4442 & $1,629.6$ & 238.6 \\
\hline hsa-miR-3665 & $22,420.0$ & $1,538.6$ & hsa-miR-4741 & $1,607.0$ & 345.4 \\
\hline hsa-miR-4484 & $21,004.0$ & 207.2 & hsa-miR-3197 & $1,600.5$ & 192.0 \\
\hline hsa-miR-762 & $20,776.0$ & $1,527.1$ & hsa-miR-3937 & $1,528.1$ & 152.4 \\
\hline hsa-miR-4739 & $18,737.0$ & 671.5 & hsa-miR-4532 & $1,467.0$ & 149.0 \\
\hline hsa-miR-4516 & $16,181.0$ & $1,884.0$ & hsa-miR-4655-5p & $1,377.6$ & 177.1 \\
\hline hsa-miR-4505 & $12,498.5$ & 443.2 & hsa-miR-3180 & $1,312.2$ & 435.1 \\
\hline hsa-miR-3648 & $12,080.7$ & 175.5 & hsa-miR-4695-5p & $1,298.0$ & 174.7 \\
\hline hsa-miR-4466 & $11,807.8$ & $1,714.7$ & hsa-miR-3180-3p & $1,172.2$ & 153.8 \\
\hline hsa-miR-4488 & $11,136.4$ & $2,385.7$ & hsa-miR-92b* & $1,163.7$ & 158.8 \\
\hline hsa-miR-3196 & $11,008.8$ & $1,971.5$ & hsa-miR-671-5p & $1,091.4$ & 106.2 \\
\hline hsa-miR-2861 & $10,473.1$ & $1,617.8$ & hsa-miR-1280 & $1,085.7$ & 180.6 \\
\hline hsa-miR-638 & $10,180.6$ & 587.0 & hsa-miR-4728-5p & $1,051.4$ & 159.1 \\
\hline hsa-miR-1908 & $9,862.2$ & 559.4 & hsa-miR-4689 & 836.7 & 166.4 \\
\hline hsa-miR-4725-3p & $9,736.2$ & 502.2 & hsa-miR-642b & 808.9 & 111.5 \\
\hline hsa-miR-4294 & $9,309.6$ & $3,504.9$ & hsa-miR-1909 & 791.7 & 139.2 \\
\hline hsa-miR-3656 & $8,587.1$ & 964.6 & hsa-miR-939 & 730.0 & 112.2 \\
\hline hsa-miR-4467 & $8,139.1$ & 446.2 & hsa-miR-4656 & 677.5 & 105.1 \\
\hline hsa-miR-4745-5p & $7,940.2$ & 495.4 & hsa-miR-3195 & 631.0 & 186.6 \\
\hline hsa-miR-4734 & $7,933.7$ & 615.8 & hsa-miR-3663-3p & 630.8 & 147.8 \\
\hline hsa-miR-4497 & $7,932.5$ & 451.3 & hsa-miR-92a-2* & 621.2 & 207.6 \\
\hline hsa-miR-744 & $6,356.6$ & 244.6 & hsa-miR-3188 & 606.1 & 132.1 \\
\hline hsa-miR-4327 & $6,287.8$ & 272.2 & hsa-miR-4486 & 565.7 & 109.2 \\
\hline hsa-miR-4723-5p & $6,007.8$ & 416.2 & hsa-miR-1202 & 559.6 & 154.5 \\
\hline hsa-miR-663 & $5,899.5$ & 576.6 & hsa-miR-4270 & 557.6 & 121.8 \\
\hline hsa-miR-3621 & $5,509.6$ & $3,186.3$ & hsa-miR-3185 & 547.7 & 102.1 \\
\hline hsa-miR-4454 & $4,467.7$ & 112.9 & hsa-miR-4649-5p & 526.5 & 169.7 \\
\hline hsa-miR-1268 & $4,115.5$ & 711.4 & hsa-miR-4688 & 454.0 & 105.3 \\
\hline hsa-miR-1246 & $3,965.1$ & $3,866.2$ & hsa-miR-4707-5p & 428.8 & 136.7 \\
\hline hsa-miR-3940-5p & $3,925.4$ & 936.0 & hsa-miR-4697-5p & 414.7 & 138.1 \\
\hline hsa-miR-4492 & $3,916.0$ & 251.9 & hsa-miR-4732-5p & 381.2 & 481.5 \\
\hline hsa-miR-3178 & $3,777.1$ & 459.8 & hsa-miR-4758-5p & 374.8 & 100.0 \\
\hline hsa-miR-1469 & $3,516.2$ & 639.1 & hsa-miR-720 & 323.1 & 145.2 \\
\hline hsa-miR-4530 & $3,463.2$ & 242.0 & hsa-miR-296-5p & 301.6 & 108.3 \\
\hline hsa-miR-1228* & 3,319.6 & 628.7 & hsa-miR-4429 & 300.4 & 105.1 \\
\hline hsa-miR-4459 & $2,894.8$ & 286.1 & hsa-miR-4433 & 238.7 & 163.4 \\
\hline hsa-miR-4687-3p & $2,760.3$ & 700.9 & hsa-miR-1290 & 226.1 & 196.4 \\
\hline hsa-miR-4463 & $2,668.5$ & 478.1 & hsa-miR-483-3p & 221.0 & 103.3 \\
\hline hsa-miR-1915 & $2,516.5$ & 185.4 & hsa-miR-4730 & 206.3 & 152.8 \\
\hline hsa-miR-1260b & $2,456.4$ & 295.3 & hsa-miR-542-5p & 193.6 & 113.9 \\
\hline hsa-miR-4281 & $2,407.2$ & 344.2 & hsa-miR-4787-3p & 193.4 & 116.6 \\
\hline hsa-miR-149* & $2,356.0$ & 257.3 & hsa-miR-320b & 148.3 & 102.1 \\
\hline hsa-miR-4749-5p & $2,305.3$ & 176.4 & hsa-miR-4443 & 123.7 & 272.6 \\
\hline hsa-miR-1275 & $2,241.6$ & 215.3 & hsa-miR-22 & 111.2 & 135.5 \\
\hline hsa-miR-1268b & $2,210.7$ & 350.2 & hsa-miR-21 & 105.8 & 149.9 \\
\hline hsa-miR-3141 & $1,979.9$ & 250.6 & hsa-miR-122 & 104.1 & 234.6 \\
\hline hsa-miR-4417 & $1,809.8$ & 425.3 & hsa-miR-17 & 101.8 & 120.9 \\
\hline
\end{tabular}




\section{Acknowledgements}

This study was supported in part by the Hirosaki University Institutional Research Grant for Young Scientists, KAKENHI (no. 23790613), a Grant-in-Aid for Young Scientists (B), a grant from KAKENHI (no. 25670264) for Challenging Exploratory Research, a grant from the Suzuken Memorial Foundation (no. 11-076), a grant from the Takeda Science Foundation, and a grant from the Ministry of Education, Culture, Sports, Science and Technology of Japan (MEXT).

\section{References}

1. Valadi H, Ekström K, Bossios A, Sjostrand M, Lee JJ and Lötvall JO: Exosome-mediated transfer of mRNAs and microRNAs is a novel mechanism of genetic exchange between cells. Nat Cell Biol 9: 654-659, 2007.

2. Hu G, Drescher KM and Chen XM: Exosomal miRNAs: biological properties and therapeutic potential. Front Genet 3: $56,2012$.

3. Arroyo JD, Chevillet JR, Kroh EM, et al: Argonaute2 complexes carry a population of circulating microRNAs independent of vesicles in human plasma. Proc Natl Acad Sci USA 108: 5003-5008, 2011.

4. Turchinovich A, Weiz L, Langheinz A and Burwinkel B: Characterization of extracellular circulating microRNA. Nucleic Acids Res 39: 7223-7233, 2011.

5. Vickers KC, Palmisano BT, Shoucri BM, Shamburek RD and Remaley AT: MicroRNAs are transported in plasma and delivered to recipient cells by high-density lipoproteins. Nat Cell Biol 13: 423-433, 2011.

6. Wang K, Zhang S, Weber J, Baxter D and Galas DJ: Export of microRNAs and microRNA-protective protein by mammalian cells. Nucleic Acids Res 38: 7248-7259, 2010.

7. Brase JC, Wuttig D, Kuner R and Sultmann H: Serum microRNAs as non-invasive biomarkers for cancer. Mol Cancer 9: 306,2010

8. Huang Z, Huang D, Ni S, Peng Z, Sheng W and Du X: Plasma microRNAs are promising novel biomarkers for early detection of colorectal cancer. Int J Cancer 127: 118-126, 2010.

9. Moon PG, Lee JE, You S, et al: Proteomic analysis of urinary exosomes from patients of early IgA nephropathy and thin basement membrane nephropathy. Proteomics 11: 2459-2475, 2011.

10. Michael A, Bajracharya SD, Yuen PS, et al: Exosomes from human saliva as a source of microRNA biomarkers. Oral Dis 16 $34-38,2010$.

11. Lässer C, Alikhani VS, Ekström K, et al: Human saliva, plasma and breast milk exosomes contain RNA: uptake by macrophages. J Transl Med 9: 9, 2011.

12. Taylor DD and Gercel-Taylor C: MicroRNA signatures of tumorderived exosomes as diagnostic biomarkers of ovarian cancer. Gynecol Oncol 110: 13-21, 2008.

13. Kosaka N, Izumi H, Sekine K and Ochiya T: microRNA as a new immune-regulatory agent in breast milk. Silence 1: 7, 2010.
14. Ge Q, Zhou Y, Lu J, Bai Y, Xie X and Lu Z: miRNA in plasma exosome is stable under different storage conditions. Molecules 19: 1568-1575, 2014.

15. Karlsson M, Lundin S, Dahlgren U, Kahu H, Pettersson I and Telemo E: 'Tolerosomes' are produced by intestinal epithelial cells. Eur J Immunol 31: 2892-2900, 2001.

16. Muturi HT, Dreesen JD, Nilewski E, et al: Tumor and endothelial cell-derived microvesicles carry distinct CEACAMs and influence T-cell behavior. PLoS One 8: e74654, 2013.

17. King HW, Michael MZ and Gleadle JM: Hypoxic enhancement of exosome release by breast cancer cells. BMC Cancer 12: 421, 2012.

18. Montecalvo A, Larregina AT, Shufesky WJ, et al: Mechanism of transfer of functional microRNAs between mouse dendritic cells via exosomes. Blood 119: 756-766, 2012.

19. Lee JK, Park SR, Jung BK, et al: Exosomes derived from mesenchymal stem cells suppress angiogenesis by down-regulating VEGF expression in breast cancer cells. PLoS One 8: e84256, 2013.

20. Escola JM, Kleijmeer MJ, Stoorvogel W, Griffith JM, Yoshie O and Geuze HJ: Selective enrichment of tetraspan proteins on the internal vesicles of multivesicular endosomes and on exosomes secreted by human B-lymphocytes. J Biol Chem 273: 20121-20127, 1998

21. Bobrie A, Colombo M, Raposo G and Thery C: Exosome secretion: molecular mechanisms and roles in immune responses. Traffic 12: 1659-1668, 2011.

22. Hanson PI and Cashikar A: Multivesicular body morphogenesis. Annu Rev Cell Dev Biol 28: 337-362, 2012.

23. Raiborg $C$ and Stenmark H: The ESCRT machinery in endosomal sorting of ubiquitylated membrane proteins. Nature 458: 445-452, 2009.

24. Trajkovic K, Hsu C, Chiantia S, et al: Ceramide triggers budding of exosome vesicles into multivesicular endosomes. Science 319: 1244-1247, 2008

25. Marchesini N, Luberto $C$ and Hannun YA: Biochemical properties of mammalian neutral sphingomyelinase 2 and its role in sphingolipid metabolism. J Biol Chem 278: 13775-13783, 2003.

26. Kosaka N, Iguchi H, Yoshioka Y, Takeshita F, Matsuki Y and Ochiya T: Secretory mechanisms and intercellular transfer of microRNAs in living cells. J Biol Chem 285: 17442-17452, 2010.

27. Lee DH, Kim SH, Ahn KH, et al: Identification and evaluation of neutral sphingomyelinase 2 inhibitors. Arch Pharm Res 34: 229-236, 2011

28. Rodriguez-Boulan E, Kreitzer G and Müsch A: Organization of vesicular trafficking in epithelia. Nat Rev Mol Cell Biol 6: 233-247, 2005

29. Jahn R and Fasshauer D: Molecular machines governing exocytosis of synaptic vesicles. Nature 490: 201-207, 2012.

30. Savina A, Vidal M and Colombo MI: The exosome pathway in K562 cells is regulated by Rab11. J Cell Sci 115: 2505-2515, 2002.

31. Ostrowski M, Carmo NB, Krumeich S, et al: Rab27a and Rab27b control different steps of the exosome secretion pathway. Nat Cell Biol 12: 19-30, 2010.

32. Söllner T, Whiteheart SW, Brunner M, et al: SNAP receptors implicated in vesicle targeting and fusion. Nature 362: 318-324, 1993. 